\title{
Temperature Dependence of Compression of Linear High Polymers at High Pressures ${ }^{1}$
}

\author{
Charles E. Weir
}

\begin{abstract}
Pressure-volume-temperature data for polyethylene, polytetrafluoroethylene, polymonochlorotrifluoroethylene, polyvinyl fluoride, polyvinylidene fluoride, polyvinyl alcohol, a copolymer of ethylene-tetrafluoroethylene (1:1), and a polyester are reported over the range $20^{\circ}$ to $80^{\circ} \mathrm{C}$ and 1 to 10,000 atmospheres. Empirical equations of state for some of the polymers are derived. Internal-energy changes were calculated for most of the polymers studied.
\end{abstract}

\section{Introduction}

Previous studies of the effects of high pressures on polymeric materials have resulted in reports on pressure-volume-temperature data on rubber-sulfur vulcanizates $[1]^{2}$ and on transitions found in Teflon [2]. The behavior of Teflon was of considerable interest, and it was decided to study the available, chemically related polymers to ascertain the extent of the uniqueness of Teflon. This report contains the data obtained for pressures as high as 10,000 atm at temperatures from $20^{\circ}$ to $80^{\circ} \mathrm{C}$. Pressurevolume-temperature data are given, and, in most instances, equations of state and thermodynamic data of interest are presented. The polymers studied were polyethylene, polyvinyl alcohol, polytetrafluoroethylene (Teflon), polymonochlorotrifluoroethylene (Kel-F), polyvinyl fluoride, polyvinylidene fluoride, a copolymer of ethylene and tetrafluoroethylene in a 1:1 ratio and a polyester. No irregularities in behavior were observed in any of these materials except Teflon.

\section{Experimental Method}

\subsection{Compression Measurements}

The procedures used for measuring isothermal compression and for temperature control have been described previously in detail $[3,1]$. The only departure from previous procedures was necessitated by the fact that certain of the polymers studied were available only in the form of powders. Such powders were measured in a steel container that was open at one end. The powders were packed into the container and impregnated with the confining liquid before measurement. In the case of the powders no irregularities were observed either in the experimental behavior or in the resulting data.

\subsection{Volume Measurements}

Volumes were measured as described previously [1] by weighing specimens in air before compression and in the confining liquid immediately following compression. These measurements were made at $21^{\circ} \mathrm{C}$ only. Volumes at other temperatures were determined from expansion data. Powdered speci-

1 This work was sponsored by the Office of Naval Research, Department of the Navy.

${ }^{2}$ Figures in brackets indicate the literature references at the end of this paper. mens were treated in a similar manner, except that corrections for the weight and volume of the container were required.

Expansion data were obtained on all samples to permit calculation of volumes at elevated temperatures from the measured volume at $21^{\circ}$ C. For Teflon the data of Quinn, Roberts, and Work [4] were utilized, since they studied a specimen cut from the same sample. For all other polymers, volumes were studied, using mercury-filled dilatometers. Temperatures were allowed to reach equilibrium before each volume measurement was made. Powdered polymers were molded into disks for such studies. The fluoride polymers are not readily molded and measurements were made on disks that were probably only sintered. Initial efforts to use such powders in water-filled dilatometers were unsuccessful due to instability of the water level. In one instance, however, reproducible data obtained, using a water-filled dilatometer agreed well with data obtained from a compressed disk in the mercuryfilled dilatometer.

\section{Specimens}

Test specimens of polytetrafluoroethylene (Teflon), polyethylene, polymonochlorotriffluoroethylene (Kel-F), and a polyester (Selectron 5003) have been described previously [5].

Polyvinyl alcohol was used in the form of a fine powder with a faint yellow color.

Polyvinyl fluoride, polyvinylidene fluoride, and the copolymer of ethylene and tetrafluoroethylene were made available through the courtesy of a commercial manufacturer of high polymers. These materials were all white powders.

\section{Results}

\subsection{Experimental Data}

The experimental results consist of the measured compressions and the corresponding PVT data derived therefrom. The experimental compressions are shown in table 1.

Compressions at $1 \mathrm{~atm}$ and $1,000 \mathrm{~atm}$ appear as negative values since $2,000 \mathrm{~atm}$ is used as a reference point. This feature along with the method used to obtain values at $1 \mathrm{~atm}$ has been discussed previously [1]. Total compression based on $1 \mathrm{~atm}$ 
TABLE 1. Compression of polymers

$-\Delta V / V_{0}$

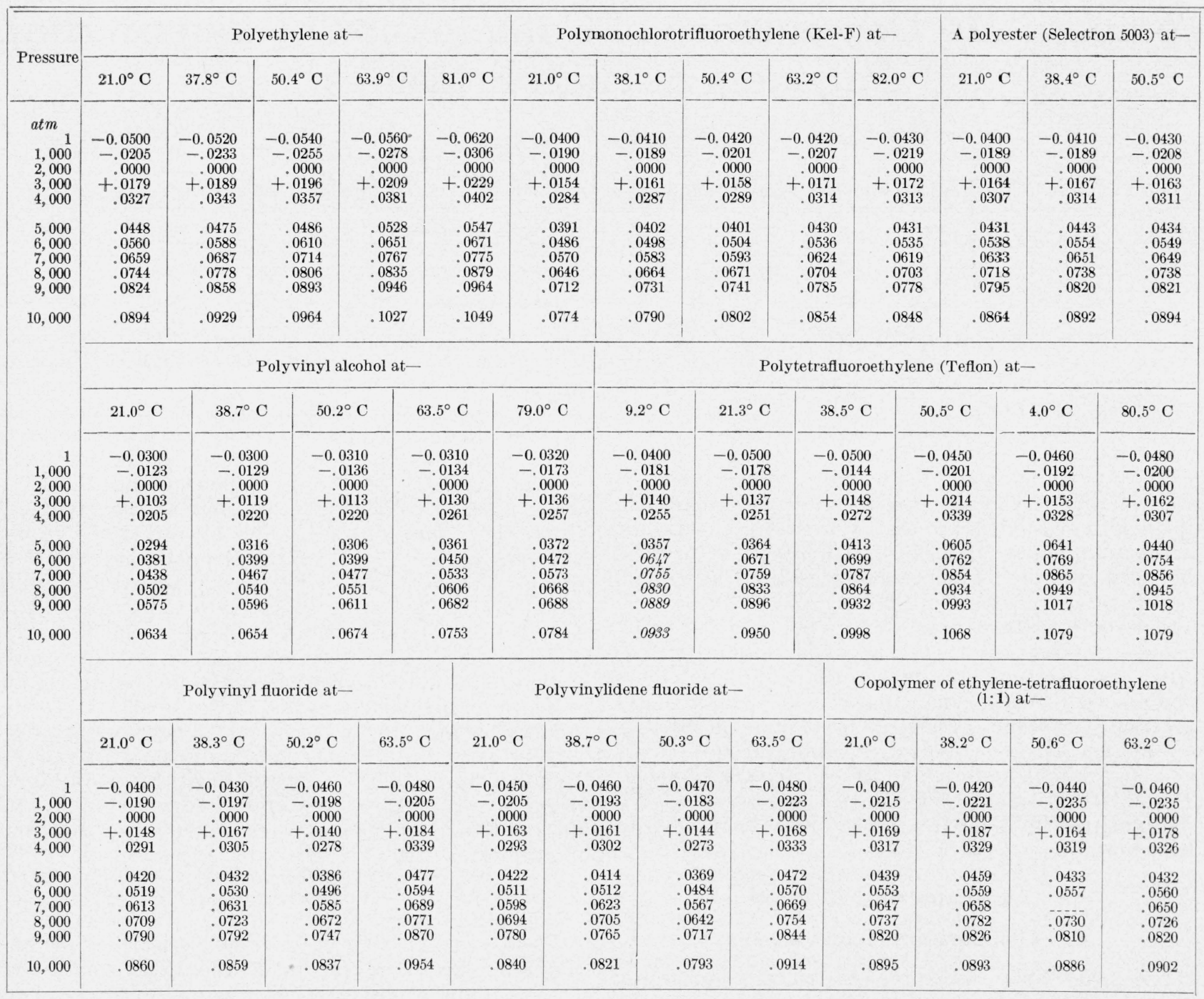

may be obtained by changing the sign of the value given at $1 \mathrm{~atm}$ and adding the resulting figure to each value in the corresponding column.

The data for Kel-F at $21.0^{\circ} \mathrm{C}$, which represent the average of two measurements, are corrected data that have been reported erroneously in an earlier report [5] through the use of an incorrectly calculated specific volume.

Italicized results shown for Teflon at $9.2^{\circ} \mathrm{C}$ represent adjusted experimental data. As noted previously [2], the transition at this temperature was very sluggish, and the values measured at higher pressures were most probably not the equilibrium values. The measured data at these pressures were therefore adjusted on the assumption that the discontinuity in volume at $9.2^{\circ} \mathrm{C}$ was the same as that measured at $21.3^{\circ} \mathrm{C}$. Evidence for the validity of this process will be shown later.

From the isothermal compression values obtained and the volume-temperature data at $1 \mathrm{~atm}$, specific volume-temperature-pressure tables were constructed. The experimental specific volumes were plotted isobarically on a large scale and smooth curves were drawn which, except for Teflon and polyethylene, consisted essentially of straight lines. The transitions encountered in Teflon necessitated the use of broken line isobars while the isobars for polyethylene exhibited considerable curvature at the higher temperatures. From the smooth curves drawn, smoothed data were read from the graphs at 10-deg-C intervals. These data are shown in table 2 and represent the basis for all subsequent calculations and for the following observations.

The expansivity of the polyethylene specimen used here agreed well with the value reported by Hunter and Oakes [6], although the specific volume differed slightly.

The 1-atm volume-temperature data for Kel-F are in fair agreement with the results of Price [7], except that the volume of the specimen studied here 
TABLE 2. Smoothed specific volume-pressure-temperature data for polymers

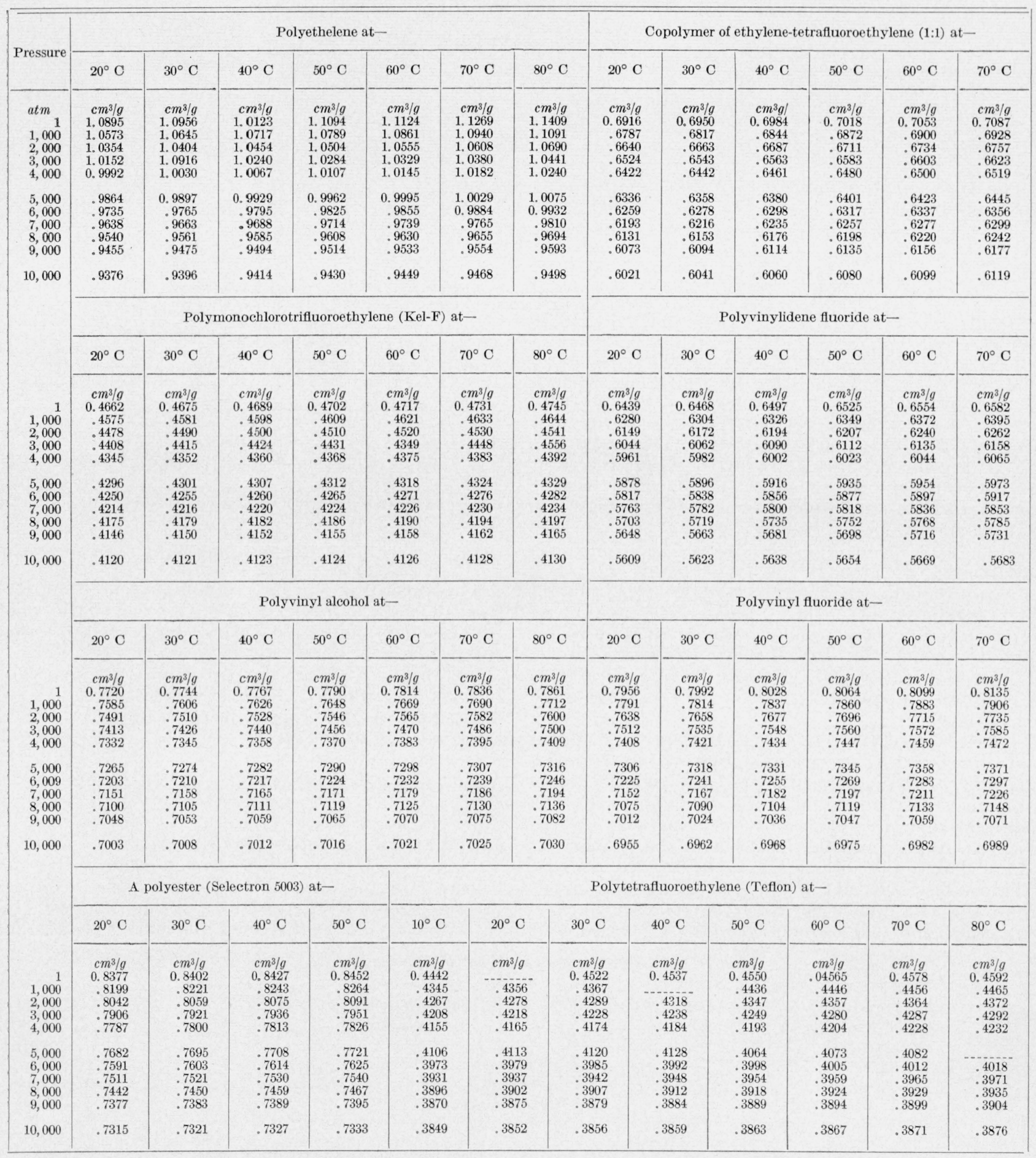

increases more rapidly at the higher temperatures. tion of the type

This increased expansivity probably arises from melting of crystalline material near $80^{\circ} \mathrm{C}$ [8].

Expansivities at $1 \mathrm{~atm}$ for the rarer polyfluorides and polyvinyl alcohol do not appear to be available. where $t$ is the temperature in degrees Celsius, and The expansivities found here were fitted to an equa- $\mid V_{0}$ is the volume of $20^{\circ} \mathrm{C}$. Appropriate values for 
TABLE 3. Coefficients of expansivity equation $\left(1 / V_{0}\right) \quad(d V / d t)=a+b \quad(t-20)$

\begin{tabular}{|c|c|c|}
\hline Polymer & $a$ & $b$ \\
\hline $\begin{array}{l}\text { Polyvinyl alcohol } \\
\text { Polyvinyl fluoride } \\
\text { Polyvinylidene fluoride. } \\
\text { Copolymer of ethylene and tetrafluoro- } \\
\text { ethylene (1:1). }\end{array}$ & $\begin{array}{r}0.000208 \\
.000353 \\
.000352 \\
.000395\end{array}$ & $\begin{array}{r}0.0000017 \\
.0000021 \\
.0000024 \\
.0000022\end{array}$ \\
\hline
\end{tabular}

$a$ and $b$ are given in table 3 for values of $t$ between $20^{\circ}$ and $90^{\circ} \mathrm{C}$.

The slightly different densities and expansivities of the 1:1 copolymer of ethylene and tetrafluoroethylene and its isomer, polyvinylidene fluoride, indicated the advisability of a check on the composition of the copolymer. A mass spectrographic analysis indicated that the ratio of ethylene and tetrafluoroethylene present in the polymer was $1: 1$. The lower initial density of the copolymer as well as its somewhat different expansivity is undoubtedly due to a lower degree of order along the polymer chains with a resulting lower packing efficiency.

The specific volumes given at $70^{\circ} \mathrm{C}$ for the rarer polyfluorides are extrapolated data since the highest temperature at which measurements were made was approximately $63^{\circ} \mathrm{C}$. However, the isobars appeared to be linear and the data are believed to be reliable.

Measurements on "Selectron 5003" were limited to a maximum of $50^{\circ} \mathrm{C}$. These data may be of interest as indicative of the behavior of a polyester and are included for that purpose. The expansivity of this material was determined dilatometrically at $1 \mathrm{~atm}$, but no equation representing the expansivity was derived.

Several blanks are noted in the specific volume data for Teflon. These are caused by uncertainties in the specific volumes at the points in question due to proximity of a transition line. The isobars for this material show an interesting behavior (fig. 1). In order to understand the behavior of the isobars the phase diagram [2] is superimposed on the isobars. The peculiar behavior of the 5,000-atm isobar arises from the fact that this isobar enters and emerges from the Teflon III region in the ranges covered.

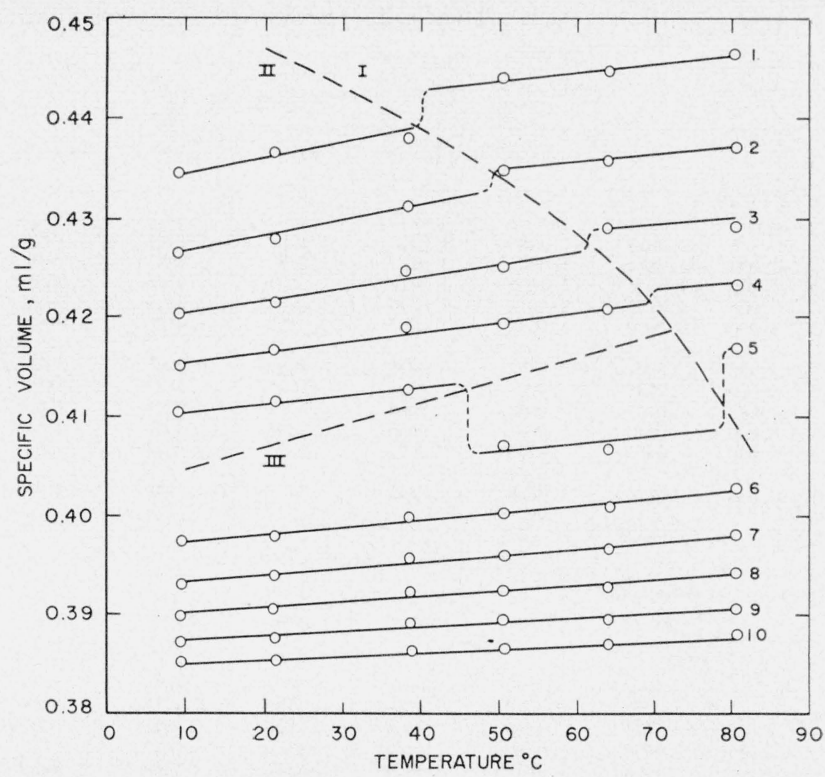

Figure 1. Isobars for Teflon.

The phase diagram is superimposed on the isobars to show their relationship to the forms of Teflon. The number at the right of each isobar represents the pressure in thousands of atmospheres.

\subsection{Calculated Data}

The preceding specific volume-pressure-temperature data have been utilized for calculations of equations of state, and work, heat, and internal energy changes.

Following in detail the procedure described for rubbers [1], empirical PVT equations of state were derived for the materials of primary interest. These equations are of the form

$$
\begin{array}{r}
V_{s p}=V_{0}\left[1+a_{1} P+a_{2} P^{2}+a_{3} P^{3}+t\left(b_{0}+b_{1} P+b_{2} P^{2}+\right.\right. \\
\left.\left.b_{3} P^{3}\right)+t^{2}\left(c_{0}+c_{1} P+c_{2} P^{2}+c_{3} P^{3}\right)\right],
\end{array}
$$

and the derived coefficients are given in table 4. Values of $P$ and $t$ are taken to be in atmospheres and degrees Celsius, respectively. In most instances the coefficients will reproduce the experimental data to within a few tenths of 1 percent, although for

TABLE 4. Coefficients of empirical PVT equation

\begin{tabular}{|c|c|c|c|c|c|c|}
\hline \multirow{3}{*}{ Coefficient } & \multicolumn{6}{|c|}{ Polymer } \\
\hline & \multicolumn{3}{|c|}{ Teflon } & \multirow{2}{*}{ Polyethylene } & \multirow{2}{*}{ Kel-F } & \multirow{2}{*}{ Polyvinyl alcohol } \\
\hline & I & II & III & & & \\
\hline $\begin{array}{l}V_{0} \ldots \ldots \\
a_{1} \ldots \ldots \\
a_{2} \ldots \ldots\end{array} a_{3}$ & $\begin{aligned} & 0.4481 \\
&- 7.03 \times 10^{-6} \\
&-1.53 \times 10^{-8} \\
& 3.32 \times 10^{-12}\end{aligned}$ & $\begin{aligned} & 0.4421 \\
&-1.27 \times 10^{-5} \\
&-3.96 \times 10^{-9} \\
& 7.37 \times 10^{-13}\end{aligned}$ & $\begin{aligned} & 0.4351 \\
&-1.994 \times 10^{-5} \\
& 8.540 \times 10^{-10} \\
&-3.050 \times 10^{-15}\end{aligned}$ & $\begin{aligned} & \text { 1. } 0881 \\
&-3.354 \times 10^{-5} \\
& \text { 3. } 511 \times 10^{-9} \\
&-1.575 \times 10^{-13}\end{aligned}$ & $\begin{array}{l}0.4636 \\
-2.127 \times 10^{-5} \\
1.363 \times 10^{-9} \\
-3.537 \times 10^{-14}\end{array}$ & $\begin{aligned} & 0.7674 \\
- & .584 \times 10^{-5} \\
& 1.178 \times 10^{-9} \\
- & 4.863 \times 10^{-14}\end{aligned}$ \\
\hline 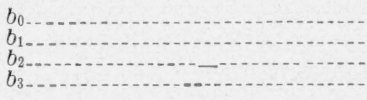 & $\begin{array}{r}3.08 \times 10^{-4} \\
-2.77 \times 10^{-7} \\
2.63 \times 10^{-10} \\
-5.31 \times 10^{-14}\end{array}$ & $\begin{array}{r}\text { 4. } 75 \times 10^{-4} \\
-1.30 \times 10^{-7} \\
\text { 4. } 30 \times 10^{-12} \\
\text { 2. } 12 \times 10^{-15}\end{array}$ & $\begin{array}{r}1.95 \times 10^{-4} \\
-3.53 \times 10^{-9} \\
-7.14 \times 10^{-13} \\
8.72 \times 10^{-18}\end{array}$ & $\begin{array}{r}-2.86 \times 10^{-5} \\
2.66 \times 10^{-7} \\
-5.92 \times 10^{-11} \\
\quad 3.44 \times 10^{-15}\end{array}$ & $\begin{array}{r}2.76 \times 10^{-4} \\
-3.90 \times 10^{-8} \\
3.73 \times 10^{-12} \\
-2.44 \times 10^{-16}\end{array}$ & $\begin{array}{r}3.01 \times 10^{-4} \\
-3.92 \times 10^{-8} \\
-1.09 \times 10^{-14} \\
1.68 \times 10^{-16}\end{array}$ \\
\hline$c_{0} c_{1} c_{2}$ & $\begin{array}{r}1.96 \times 10^{-8} \\
\text { 1. } 00 \times 10^{-9} \\
-1.56 \times 10^{-12} \\
3.37 \times 10^{-16}\end{array}$ & $\begin{array}{r}0 \\
1.10 \times 10^{-11} \\
\text { 5. } 29 \times 10^{-14} \\
-1.53 \times 10^{-17}\end{array}$ & $\begin{array}{l}0 \\
0 \\
0 \\
0\end{array}$ & $\begin{array}{r}7.73 \times 10^{-6} \\
-3.85 \times 10^{-9} \\
6.70 \times 10^{-13} \\
-3.58 \times 10^{-17}\end{array}$ & $\begin{array}{r}2.35 \times 10^{-7} \\
-9.21 \times 10^{-11} \\
-5.84 \times 10^{-16} \\
9.94 \times 10^{-19}\end{array}$ & $\begin{array}{r}3.18 \times 10^{-8} \\
1.67 \times 10^{-11} \\
-1.41 \times 10^{-15} \\
-5.38 \times 10^{-20}\end{array}$ \\
\hline
\end{tabular}

$V_{\mathrm{sp}}=V_{0}\left[1+a_{1} P+a_{2} P^{2}+a_{3} P^{3}+t\left(b_{0}+b_{1} P+b_{2} P^{2}+b_{3} P^{3}\right)+t^{2}\left(c_{0}+c_{1} P+c_{2} P^{2}+c_{3} P^{3}\right)\right]$ 
Teflon I and Teflon II the discrepancy is somewhat larger. The larger deviations for these two materials are probably due to the smaller amount of data available for fitting the equations.

It must be emphasized that these equations are designed to reproduce only $V_{s p}$ within the range in which measurements were made. Extrapolation in any sense may lead to serious errors, as shown by the sign of $b_{0}$ for polyethylene. The equations likewise have not been examined analytically. The first partial derivatives appear to yield reasonable values, which do not always agree with the experimental expansivities and compressibilities within the experimental error. Thereíore, deductions based on first and higher derivatives of these equations must be made with caution.

In most instances the values of the $c$ terms will be found to be negligible except at high pressures and temperatures. Inasmuch as these values are of importance in some instances, they are recorded. In the case of 'Teflon III, the term involving $t^{2}$ was identically zero.

Similar equations were not derived for the rarer fluorine polymers because the amount of data available were limited, and these materials are of more academic interest at present. However, such equations can be derived from the data if required.

From the tabulated specific volume-pressuretemperature data, values for work of compression $\left(w=\int P(\partial V / \partial P)_{T} d P\right)$, heat of compression $\left(q=-T \mathcal{S}(\partial V / \partial T)_{P} d P\right)$, and internal-energy change $(\Delta E=q-w)$ were calculated [9]. Work and heat values were computed by mechanical integration [10] under appropriate curves constructed from the PVT data. The internal-energy changes were then calculated from the corresponding work and heat data. Complete data for work and heat values are not reported, but the calculated internal energy changes are shown graphically in figures 2 to 8 . The changes in internal energy represent the energy in joules per gram (j/g) evolved or absorbed on an isothermal compression from $1 \mathrm{~atm}$ to the pressure given by the abscissa.

It is to be noted that graphical integrations for all materials except Teflon are straightforward. For Teflon the integration for heat values is complicated by the latent heats of the two transitions encountered. The value of latent heat reported by Furukawa [11] was taken to apply at all pressures in transforming I to II. This assumption is most probably in error at the higher pressures, since the shape of the I-II line is curved and $\Delta V_{\text {I-II }}$ changes markedly. However, a more reliable estimate of the latent heat cannot be made from the present data. This heat is evolved on compression. Latent heats absorbed in forming III from II were calculated from the Clapeyron equation and are tabulated in a following section. Sufficient data are not available for a reliable calculation of the latent heat involved in the I-III transition. Values of heat of compression involving this quantity and the corresponding internal-energy changes could not be calculated.

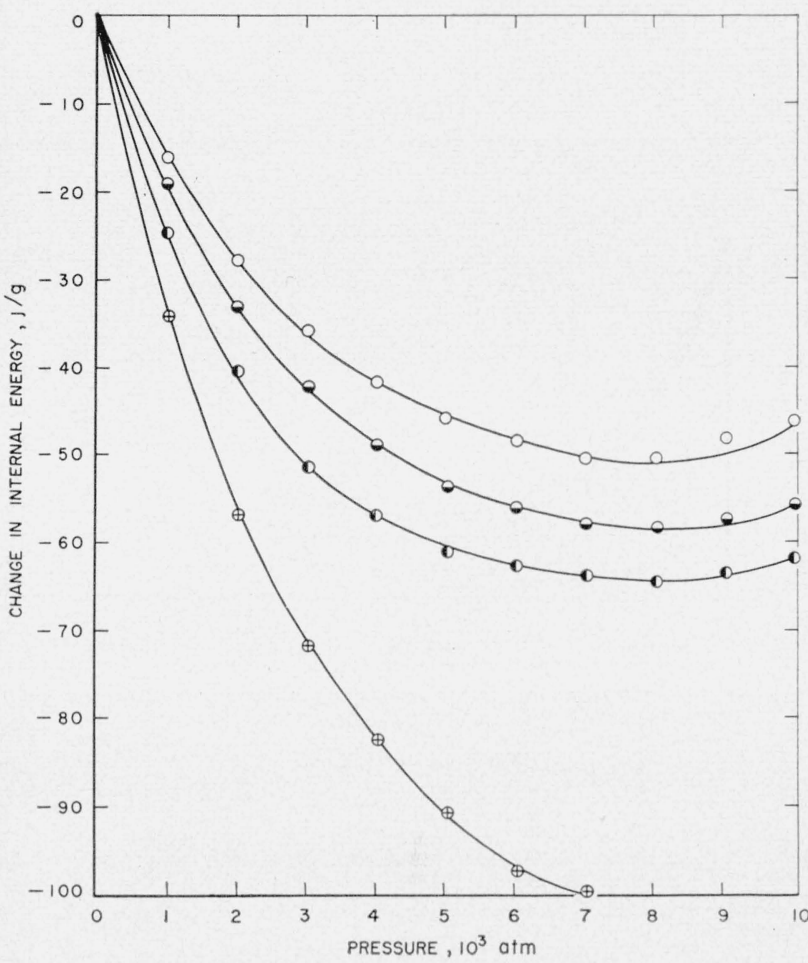

FIGURE 2. Change in internal energy on compression of polyethylene.

$\mathrm{O}, 20^{\circ} \mathrm{C} ; \bullet, 40^{\circ} \mathrm{C} ; 60^{\circ} \mathrm{C} ; \oplus, 80^{\circ} \mathrm{C}$.

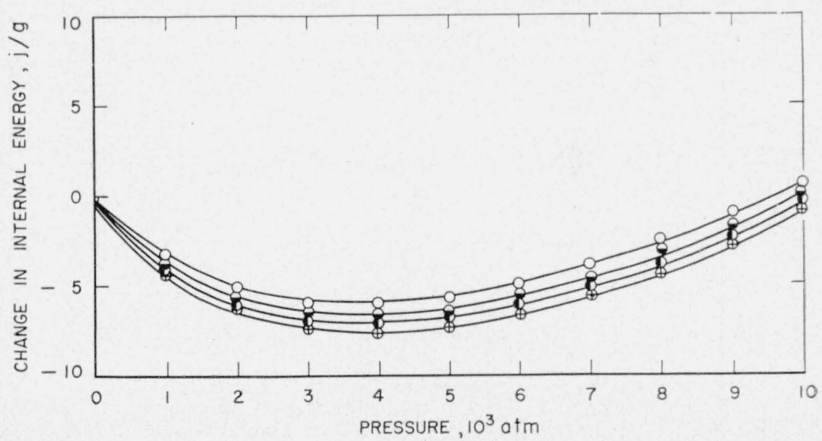

Figure 3. Change in internal energy on compression of Kel-F. $\bigcirc, 20^{\circ} \mathrm{C} ; \odot, 40^{\circ} \mathrm{C} ; \mathbf{C}, 60^{\circ} \mathrm{C} ; \oplus, 80^{\circ} \mathrm{C}$.

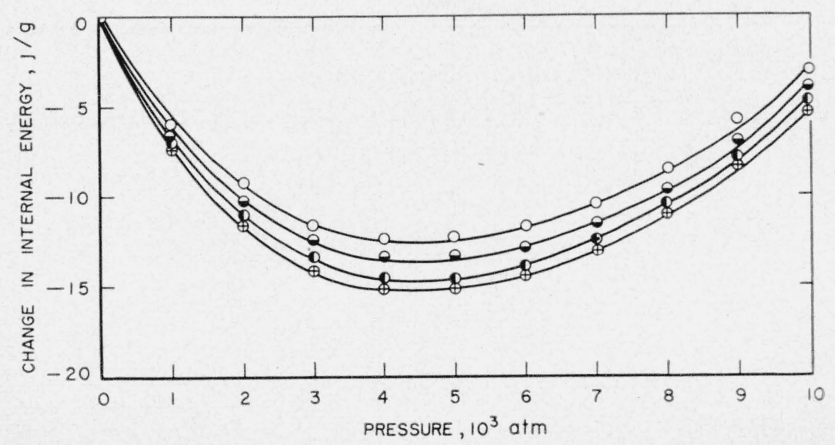

Figure 4. Change in internal energy on compression of polyvinyl alcohol.

$\bigcirc, 20^{\circ} \mathrm{C} ; \bullet, 40^{\circ} \mathrm{C} ; \mathbf{C}, 60^{\circ} \mathrm{C} ; \oplus, 80^{\circ} \mathrm{C}$ 


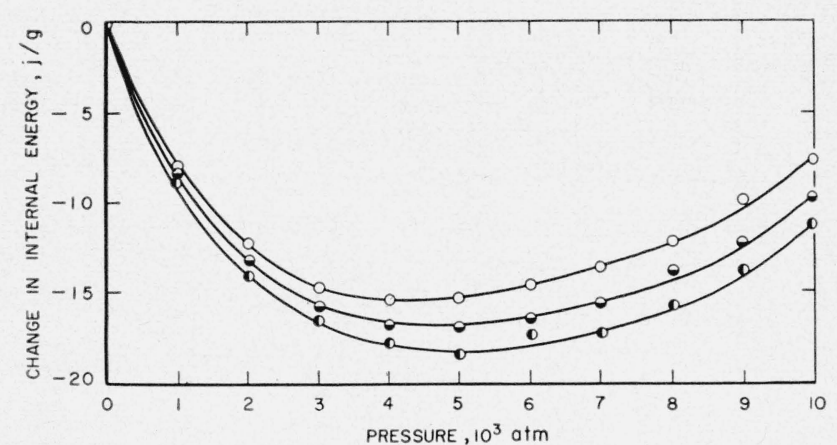

Figure 5. Change in internal energy on compression of polyvinyl fluoride.

$\bigcirc, 20^{\circ} \mathrm{C} ; \bullet, 40^{\circ} \mathrm{C} ; \boldsymbol{\oplus}, 60^{\circ} \mathrm{C}$.

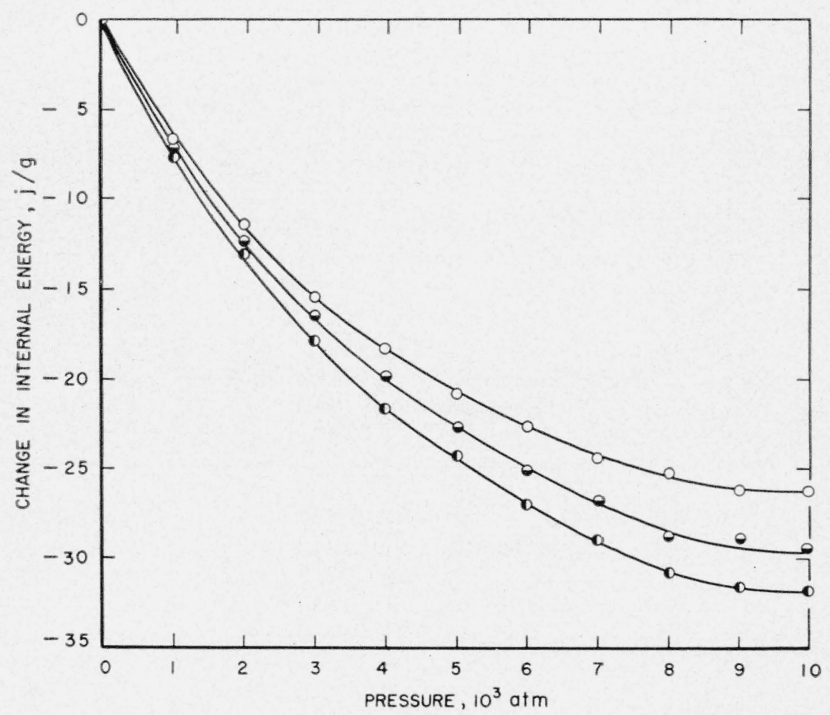

FIGURE 6. Change in internal energy on compression of polyvinylidene fluoride.

○, $20^{\circ} \mathrm{C} ; \boldsymbol{\nabla}, 40^{\circ} \mathrm{C} ; \boldsymbol{C}, 60^{\circ} \mathrm{C}$.

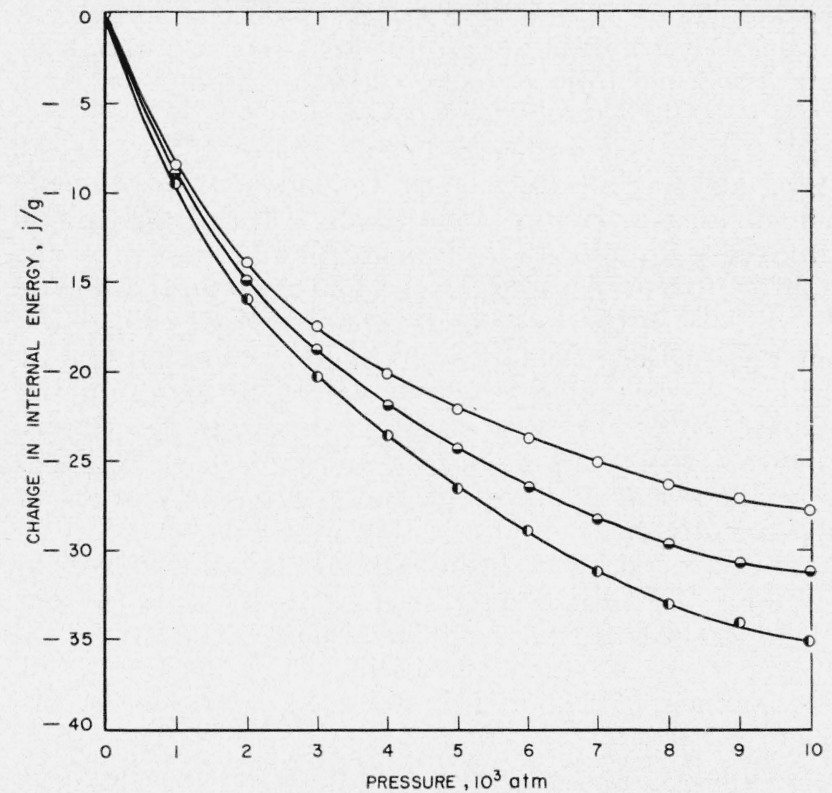

FIGURE 7. Change in internal energy on compression of copolymer.

$\mathrm{O}, 20^{\circ} \mathrm{C} ; \boldsymbol{\bullet}, 40^{\circ} \mathrm{C} ; \boldsymbol{\oplus}, 60^{\circ} \mathrm{C}$.

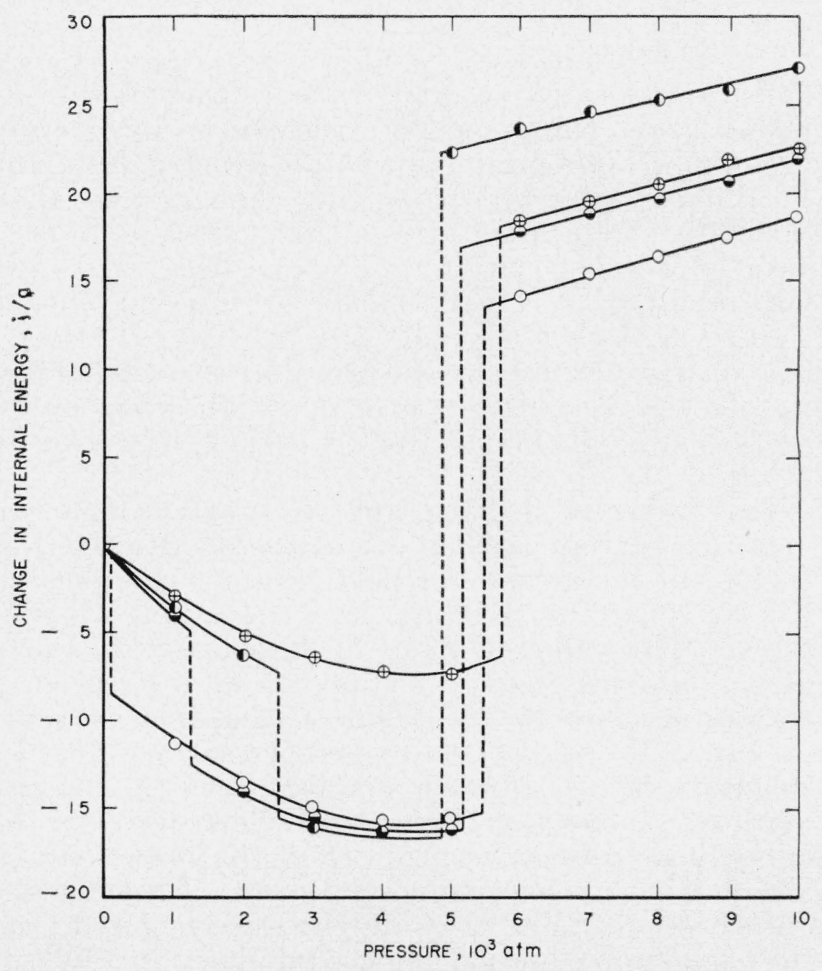

FIGURE 8. Change in internal energy on compression of Teflon $\oplus, 10^{\circ} \mathrm{C} ; \mathrm{O}, 20^{\circ} \mathrm{C} ; \boldsymbol{\ominus}, 40^{\circ} \mathrm{C} ; \mathrm{C}, 60^{\circ} \mathrm{C}$. 


\section{Discussion}

Considering first the numerical magnitude of the compressions shown in table 1 , it is noted that these values are, in general, of the same order as those previously obtained for rubbers [10]. The comparative compression is directly proportional to the density, as has been noted by Bridgman, except for Teflon, which shows the highest compression. This anomaly arises from the transitions encountered, the Teflon being relatively incompressible. It may be noted that at still higher pressures polyethylene shows a greater compression than Teflon, despite the transitions in the latter [12].

Certain deductions may be drawn from the behavior of the internal energy. Bridgman [9] has proposed that the observed change in internal energy as the pressure is varied isothermally may be explained on the basis that the intermolecular forces are normally predominantly attractive. On compression the potential energy decreases, and the internal energy, therefore, decreases. However, at some compressed volume the process must reverse because the intermolecular forces utlimately become repulsive. Hence, on increasing the pressure, the internal-energy change decreases, then reverses direction and increases, ultimately becoming increasingly positive. The comparative behavior of the internal-energy change may be used for a qualitative comparison of the intermolecular forces.

In polyethylene (see fig. 2) the internal-energy change reverses direction within the pressure range investigated at the lower temperatures but does not become positive. This is similar to the behavior in rubbers [10]. The marked differences in behavior at the elevated temperatures is probably connected with the melting of crystalline material in this region or may be due to attack of the polyethylene by the confining liquid at these temperatures. Although inert at lower temperatures, the confining liquid severely attacked the surface of the polyethylene at $80^{\circ}$ C. Kel-F, Teflon, polyvinyl alcohol, and polyvinyl fluoride all exhibit reversal in direction of $\Delta E$ at moderate pressures, an indication of strong repulsive forces. In Kel-F alone $\Delta E$ becomes zero or positive in this pressure range but only at temperatures below about $40^{\circ} \mathrm{C}$. The behavior is not clearly shown by Teflon because of the complications of the transitions. Polyvinyl alcohol differs appreciably from polyethylene, a result that is probably due, in part at least, to the effects of hydrogen bonds. Polyvinyl fluoride differs markedly from the behavior exhibited by the polyvinlidene fluoride and copolymer in which the pressure of reversal appears to be just outside the pressure range used here.

In Teflon (see fig. 8), the II-III transition appears to occur at pressures slightly higher than that required to cause the internal-energy change to reverse direction. The forces at these and higher pressures will be essentially repulsive. Under these circumstances the formation of III from II requires a further decrease of volume against increasingly strong repulsive forces and must result in a greatly increased potential energy. The absorption of heat that attends this decrease in volume may be understood if the work performed on contraction is insufficient to supply the increased potential and possibly kinetic energies demanded. From the same viewpoint the liberation of energy in the transition I-II occurring in the region of attractive forces is to be expected. The previously reported anomalies in energies at the triple point [2] are indicated by the incongruous temperature dependence of the internal energy at the higher pressures. The inconsistencies are probably more apparent than real, however, since the latent heat of the I-II transition has been taken as independent of pressure, an assumption that is probably far from true. No alternative exists at present because the $\Delta V$ values are not reliably known except at $1 \mathrm{~atm}$.

The transition II-III was studied in some detail and, following Bridgman [9], differences between the properties of these forms may be evaluated. From the temperature dependence of the transition pressure and the measured volume discontinuities the latent heat can be calculated from the Clapeyron equation. Pertinent data calculated from the experimental results are given in table 5. Inasmuch as the transition II-III is not very sharp except at higher temperatures [2], the data of the table, as well as subsequently calculated values, cannot be considered as more than approximate.

From Bridgman's relationships [9] $d(\Delta V) / d P=$ $\Delta \alpha d T / d P-\Delta \beta \quad$ and $\quad d(\Delta H) / d P=\Delta C_{p} d T / d P-T \Delta \beta$, where $\alpha$ and $\beta$ are expansivity and compressibility, respectively, and the other terms have the usual significance. Values for $\Delta \alpha$ and $\Delta C_{p}$ can be calculated from the data of the table. These are $\Delta \alpha=\alpha_{\text {II }}$ $-\alpha_{\mathrm{III}} \approx 40 \times 10^{-6} /{ }^{\circ} \mathrm{C}$ and $\Delta C_{p}=C_{p_{\mathrm{II}}}-C_{p_{\mathrm{III}}} \approx 0.18 \mathrm{j} / \mathrm{g}$ per ${ }^{\circ} \mathrm{C} . \quad \Delta V / V_{0}=\left(V_{\text {II }}-V_{\text {III }}\right) / V_{0}$ was taken to be 0.025 .

TABle 5. Transitional data for Teflon II-III

\begin{tabular}{|c|c|c|c|c|}
\hline \multirow{2}{*}{$\begin{array}{l}\text { Tempera- } \\
\text { ture }\end{array}$} & \multirow{2}{*}{$\begin{array}{l}\text { Volume } \\
\text { discon- } \\
\text { tinuity }\end{array}$} & \multirow{2}{*}{$\begin{array}{c}\text { Latent } \\
\text { heat }\end{array}$} & \multicolumn{2}{|c|}{ Compressibility } \\
\hline & & & II & III \\
\hline${ }^{\circ} \mathrm{K}$ & $\mathrm{cm}^{3} / \mathrm{g}$ & $j / g$ & atm-1 & $a t m^{-1}$ \\
\hline $\begin{array}{l}295 \\
312 \\
323 \\
337\end{array}$ & $\begin{array}{r}0.0467 \\
.0518 \\
.0542 \\
.0570\end{array}$ & $\begin{array}{l}-24.5 \\
-28.6 \\
-31.1 \\
-34.0\end{array}$ & $\begin{array}{l}\text { 1. } 18 \times 10^{-5} \\
\text { 1. } 19 \\
\text { 1. } 20 \\
1.24\end{array}$ & $\begin{array}{l}0.75 \times 10^{-} \\
.72 \\
72 \\
.76\end{array}$ \\
\hline
\end{tabular}

Similar calculations are precluded for the I-II transition because of the small $\Delta V$ values at the higher pressures at which accurate measurements are possible. Compression curves show that II is less compressible than I [2]; Furukawa [11] has shown that $C_{p_{\mathrm{I}}}$ is greater than $C_{p_{\mathrm{II}}}$; whereas Quinn, Roberts, and Work [4] showed that $\alpha_{\mathrm{I}}$ is greater than' $\alpha_{\mathrm{II}}$. The differences in compressibilities cannot be estimated reliably, and reference should be made to the data cited for information on $C_{p}$ and $\alpha$ at $1 \mathrm{~atm}$. 
In a general discussion of the data presented here the following remarks may be made:

No comparable data appear to exist for high polymers to permit comparisons of results. Parks and Richards [13] have reported PVT data for polyethylene that cover a wider temperature range but are limited to a maximum pressure of $2,000 \mathrm{~atm}$. Their results are clearly of the same order of magnitude.

It will be noted that specific heat data are available for three of the polymers studied. Raine, Richards, and Ryder [14] and Dole, Hettinger, Larson, and Wethington [15] have reported data for polyethylene, and Hoffman [16] has reported on Kel-F. These data were all determined at relatively high temperatures, approximately $-20^{\circ} \mathrm{C}$ being the lowest temperature studied. Furukawa [11] has reported data on Teflon that extends to very low temperatures. These data can be utilized with the results of this report to calculate all the thermodynamic quantities of interest for these three materials in the pressuretemperature range studied here.

It is also noted that some uncertainty exists in values reported here betweeen 1 and $1,000 \mathrm{~atm}[3,5]$ because the measurements did not cover this pressure interval. Such uncertainty in no way affects the validity of the changes reported between 1,000 and $10,000 \mathrm{~atm}$. In addition, the compression between 1 and 1,000 atm, which was arrived at by successive approximations, is not expected to be seriously in error.

The finding that Teflon alone of the polymers studied was found to exhibit polymorphism is not surprising. From Bridgman's [9] studies it is known that polymorphism at high pressures is not a rare occurrence. In polymers, however, it is most likely to be very rare. This probability follows from the consideration that a high degree of crystallinity is most likely a requirement for polymorphism. This requirement cannot be met by more than a few known polymers. It must be pointed out, however, that the pressure-temperature range investigated here is limited and the possibility exists that the effects sought may exist outside this range.

The question arises as to the effect of molecular weight on these data. In this pressure range, two processes appear to be involved [9], first removal of "holes" and second, distortion of the molecules or atoms. The second process is probably relatively inactive at the lower pressures, whereas the first will probably occur over this whole pressure range but diminishing in effect with increasing pressure. The number of "holes" is expected to vary with the molecular weight (i. e., with the number of chain ends). However, it is expected that this variation will be most marked in extremely low molecular weights and become of decreasing importance as the molecular weight increases. For high molecular weights, therefore, it is believed that the molecular weight will have a rather small influence on compressibility. Bridgman [12] has reported data on polyethylene that verify this expectation. The materials studied here are for the most part insoluble at room temperature, and hence molecular weight data were not obtained. The results, however, are believed to be representative of such materials of high molecular weight. Furthermore, as all polymers studied possess a $\mathrm{C}-\mathrm{C}$ chain structure, which will behave similarly to a first approximation at least, the differences noted most probably are due to differences in interchain forces and free volumes.

\section{References}

[1] C. E. Weir, J. Research NBS 50, 153 (1953) RP2403.

[2] C. E. Weir, J. Research NBS 50, 95 (1953) RP2395.

[3] C. E. Weir, J. Research NBS 45, 468 (1950) RP2160.

[4] F. A. Quinn, D. E. Roberts, and R. N. Work, J. Appl. Phys. 22, 1085 (1951).

[5] C. E. Weir, J. Research NBS 46, 207 (1951) RP2192.

[6] E. Hunter and W. G. Oakes, Trans. Faraday Soc. 41, 49 (1945).

[7] F. P. Price, J. Am. Chem. Soc. 74, 311 (1952).

[8] C. E. Weir (unpublished data).

[9] P. W. Bridgman, The physics of high pressure (G. Bell \& Sons, Ltd., London, England, 1949)

[10] C. E. Weir, J. Research NBS 50, 321 (1953) RP2421.

[11] G. T. Furukawa, R. E. MeCoskey, and G. J. King, J. Research NBS 49, 273 (1953) RP2364.

[12] P. W. Bridgman, Proc. Am. Acad. Arts and Sci. 76,71 (1948)

[13] W. Parks and R. B. Richards, Trans. Faraday Soc.45, 203 (1949).

[14] H. C. Raine, R. B. Richards, and H. Ryder, Trans. Faraday Soc. 41, 56 (1945).

[15] M. Dole, W. Hettinger, N. Larson, and J. Wethington, J. Chem. Phys. 20, 781 (1952).

[16] J. Hoffman, J. Am. Chem. Soc. 74, 1696 (1952).

Washington, May 18, 1954 